\section{Verticality, Regulatory Focus, and Prices: Who is Able to Get a Good Deal?}

\author{
Marconi Freitas da Costa ${ }^{1}$ \\ marconi_costa@hotmail.com | (D) 0000-0001-9888-8359 \\ Claudio Felisoni de Angelo ${ }^{2}$ \\ cfa@usp.br | @0000-0002-6034-8282 \\ Salomão Farias ${ }^{1}$ \\ saf@ufpe.br | (D)0000-0001-5415-2606
}

\begin{abstract}
The use of the metaphor of verticality may affect consumers' motivations to perform product price assessments, and the motivational regulatory focus of the individual may have features that contribute to restoring motivation. This study aims to analyze the influence of the verticality metaphor, and of the regulatory focus on price assessments in order to get a good deal. We performed an experimental study with a design 2 (vertical metaphor: physically tall vs. physically short) x 2 (regulatory focus: promotion vs. prevention) between subjects. The results show that the treatment group, with the individuals who consider themselves physically tall and focused on prevention, had the best performance when assessing price in the context of getting a good deal. The originality of this research lies in the identification of the behavioral characteristics of individuals that are able to mitigate changes in people's motivation when exposed to mental simulations of verticality, in order to get a good deal. In practical terms, the findings make it evident that the decrease in individuals' motivation for decision making surrounding prices, under the effects of verticality, can be reestablished when they take on surveillance behavior as well as behavior aimed at avoiding mistakes.
\end{abstract}

\section{KEYWORDS}

Metaphor, Verticality, Regulatory Focus, Price, Good Deal.
${ }^{1}$ Universidade Federal de Pernambuco, Recife, PE, Brasil

${ }^{2}$ Universidade de São Paulo, São Paulo, SP, Brasil

Received: 04/08/2019.

Revised: 07/26/2019.

Accepted: 09/02/2019.

Published Online: 04/06/2020.

DOI: http://dx.doi.org/10.15728/bbr.2020.17.3.4 


\section{INTRODUCTION}

The literature on price investigations is still relatively small, given the importance of prices on business-consumer interaction (Avlonitis \& Indounas, 2007; De Toni \& Mazzon, 2013; Hanna, Lemon \& Smith, 2019). There is even less research that seeks to understand the impacts of pricing strategies on the individual's well-being (Sarkar, 2016). Thus, this research has, among other objectives, the purpose of contributing to the understanding of consumer behavior what makes a consumer act without a motivation to get the best price, when there are many offers on the market.

Individuals' patterns of decision regarding pricing is not restricted to the rational forces involved in cost-benefit analyses (Juan, Hsu \& Xie, 2017). As consumer experiences differ greatly in regards to outcomes to their decision making (Ariely, 2008; Papi, 2018), with some of them getting good results on choosing the most advantageous price and other consumers failing to perform as well (Nunes, Flores \& Silva, 2018), it is believed that there are intrinsic backgrounds to each subject that influences the motivation to make a successful decision (Silva, Santana \& Costa, 2018).

The studies by Ostinelli, Luna and Ringber (2014) found evidence of the effects of the verticality metaphor on the individuals' motivation to make decisions. The results show that, when people move mentally toward a higher level, they receive an increase in self-esteem and, in turn, individuals with high self-esteem lose interest or motivation to succeed in cognitive tasks. On the other hand, mentalizing toward a lower level leads to a decrease in self-esteem, and individuals with this low self-esteem seek to restore their ego with the motivation to achieve success in any task.

Also influencing changes of motivation among individuals is the regulatory focus theory, which features two different regulatory foci, the promotion focus and the prevention focus. According to Pham and Chang (2010), one aspect of the focus on promotion, which is grounded in anxiety, is a major concern to seize opportunities. In turn, a focus on prevention, based on surveillance, is characterized by a major concern to avoid errors (Zou \& Chan, 2019). Thus, promotionfocused individuals have a strong motivation to maximize "hits" and minimize "failures" (errors of omission), while prevention-focused individuals are motivated to maximally "correct rejections" and to minimize "false alarms". (errors of concession) (Aaker \& Lee, 2001; Zhu \& Meyers-Levy, 2007; Hanke, Rohmann \& Forster, 2019). These different motivational forces can affect the way individuals engage in getting a good deal on the market.

The use of theories that border on applied social sciences should be explored in the pursuit of knowledge (Marketing Science Institute - MSI, 2012-2014, priority Nb. 1), such as psychology (represented here by the metaphor of verticality and by the regulatory focus). Thus, the main significance of this research is the investigation of psychological procedures underlying individuals who are able to restore motivation to get a good deal, to choose the best price for a product / service.

The motivational regulatory focus plays an important role in this research, as it presents a possibility to moderate effects of the verticality metaphor on price assessments. Although regulatory focus is a widely used construct in consumer psychology research (for example, Trudel, Murray \& Cotte, 2012; Mosteller \& Poddar, 2017; Sun, Keh \& Lee, 2019), it was noticed, from a literature review, that there was a research gap, as none of the studies took into account the moderating role of the regulatory focus for situations where individuals present motivational changes before performing price assessments. Thus, the purpose of this paper is to analyze verticality metaphor effects on the way individuals perform price assessments while seeking a deal, which is when the 
individual gets the benefit of the product while paying the lowest price, having the regulatory focus as a moderator of this relationship.

\section{THEORETICAL FRAMEWORK}

\subsection{Metaphor of Verticality and Motivation}

One of the main concepts addressed by this study is the verticality (physical height), in which an individual may find himself, or perceive himself, at a given moment. This is a physical position (tall or short). Some studies have been conducted that demonstrate the effects of verticality on individuals' behaviors or decisions. For example, the study by Aggarwal and Zhao (2015) shows that physical height, or even the simple concept of height, can affect the level of mental interpretation. Consumers who perceive themselves as being physically "tall" are more likely to adopt global perception processing and a higher level of conceptual interpretation, while those who perceive themselves as being physically "short" are more likely to adopt local perception processing and a lower level of conceptual interpretation. This difference in the interpretation level also affects the product options that involve trade-offs between long-term benefits and short-term effort.

Ostinelli, Luna and Ringberg (2014) found an unexpected consequence of verticality effects on self-esteem and the individuals' behavior. The results of their study show that people who mentally simulate moving upwards (for example, taking an elevator up to go to the upper floors) increase self-esteem, this causes a decrease in motivation to succeed in a later task, thus worsening the performance of this task. In turn, when individuals imagine themselves moving downward, their self-esteem is decreased, resulting in an increased motivation to succeed in later tasks, as a way of restoring the ego.

Whereas in the research by Ostinelli, Luna and Ringberg (2014), self-esteem (high or low) is related to changes in the individual motivation, it is important to conceptualize this construct. Motivation is a theoretical construct used to explain the behavior and represents the reasons for people's actions, desires and needs (Maehr \& Meyer, 1997). Motivation can also be defined as the one's predisposition toward a behavior, or what causes a person to want to repeat a behavior and vice versa (Elliot \& Covington, 2001). Regarding consumer motivation, Berkman et al. (1997) state that motivation represents the attempt of individuals to meet his or her physiological and psychological needs through the purchase and consumption of a product.

This research is based on the findings of Ostinelli, Luna and Ringberg (2014)'s study and seeks to advance the understanding of a way to moderate the effects of the verticality metaphor on the individuals' performance, especially on price assessment activities, that consumers face routinely.

\subsection{Regulatory Focus}

Another main concept of this research is the regulatory focus that can be defined, according to Higgins (1997), as a motivational principle that explains the relationship of motivation, selfregulation, and the pursuit of an individuals' goals. This relationship shows how the individual is motivated to approach the desired end state, either through the focus on promotion, which seeks to seize opportunities, or through the focus on prevention, which prioritizes the pursuit of safety (Pham \& Chang, 2010; Mosteller \& Poddar, 2017).

The focus on promotion, in which an individual strives to achieve their ideals, reflects a motivation to approach gains or successes. Represented visually, this approach orientation can be 
BBR

17

312

thought as a vector which points the self until the target, in the direction of the desired movements (Roy \& Phau, 2014). In contrast, the focus on prevention, in which individuals strive to achieve their duties, reflects a motivation to avoid loss.

For Pham and Higgins (2005) the focus on promotion comes from the control of growth needs, as well as needs for physical and emotional care, and is especially active in the pursuit of desires, dreams, and aspirations. In turn, the focus on prevention comes from the need to have control over the individual protection (physical protection - safety) and for the protection of properties and facilities (security) and is most active in the pursuit of responsibilities and obligations (Costa, Farias, \& Angelo, 2018).

\subsection{Price Assessments for Getting a Good Deal}

According to Schindler (1998) people feel responsible for achieving a discount price, they feel proud to have achieved the discount, in place of a discount already offered by the company. Furthermore, the enthusiasm (or excitement) that is often generated by obtaining a promotional price suggests that there is a significant ego boosting aspect involved (Ostinelli, Luga \& Ringberg, 2014).

It is not hard to find in society, whether amoung family or groups of friends, individuals who want to tell others about the low prices they were able to find (Chen, Monroe \& Lou, 1998). Some surveys provide ample evidence that the feeling of being a smart consumer (smart shopper feelings) is an outstanding result because the individual was capable of achieving the promotional price (Darke \& Dahl, 2003; Nakhata \& Kuo, 2016).

The price paid by the consumer may have some consequences, among which the relevance to the ego can be highlighted (Mittal \& Biswas, 2016). Paying a low price for a particular product may lead the consumer to feel proud, smart, and competent. There may be a sense of accomplishment or a sense of victory over large corporations (Schindler 1989). Similarly, an individual may also be pleased to use this experience of getting a low price to help others to get the same price (Bicen \& Madharavam, 2013; Audrain-Pontevia, N’Goala \& Poncin, 2013).

\subsection{Verticality and Focus on Getting a Good Deal}

When assessing a 'good deal' the price needs to be carefully analyzed in order to see if the benefits to be acquired are in line with the prices charged, making sure that the amount paid is such that it does not neglect the best deal that could be achieved by the consumer. That is, a good deal would be to pay the lowest price and get the greatest possible benefit. Schindler (1998) points out that getting a discount price, or receiving a good deal, makes individuals proud of themselves and this achievement is expressive to the ego.

The study by Ostinelli, Luna and Ringberg (2014) states that individuals who were in the condition of imagined downward movement (consequently, with low self-esteem) were able to perform better in order to get a good deal because such activity is relevant to restore the ego. It is believed here that the focus on prevention will alter this outcome, effectively contributing to restoring the lost motivation of the individuals who are in the simulated condition of moving upwards. This scenario is assumed because, according to Crowe and Higgins (1997), the focus on prevention has the characteristic and surveillance strategy that states the absence of negative results (meaning no losses) and ensures that there is no presence of negative results (meaning losses).

It is noteworthy that the focus on prevention has a more conservative approach, compared to the focus on promotion which treats goals as ideals and its strategy is to get as close as possible to the earnings and move away as far as possible from the non-earnings (Pham \& Chang, 2010). The distinction between the two foci in the way they seek to achieve their goals and the desired 
end state leads to the belief that the motivation of the prevention focus is greater for getting a good deal, having in view the profile of constant attention and vigilance in avoiding negative results. In other words, the feeling of protecting oneself, or exposing oneself less, is perhaps a stronger driving force in bringing about more careful human behavior on price assessments because people are more sensitive to losses than to earnings (Kahneman \& Tversky 1979; Ariely 2008).

To test these arguments three hypotheses were drawn up crossing the groups manipulated in the study. In the first two hypotheses ( $\mathrm{H} 1 \mathrm{a}$ and $\mathrm{H} 1 \mathrm{~b}$ ) comparisons are made of the focus on prevention (when the individual considers himself physically tall) with the two situations of verticality (tall and short) having reinforced focus on promotion. It is believed that the focus on prevention will be able to have a more striking effect on those from the individuals' group who consider themselves physically tall, considering its characteristic to make people to be more careful in their decisions. It is considered that the focus on promotion, due to the characteristics mentioned above, will have no effect on restoring the individuals' motivation, regardless of their verticality position.

H1a: Individuals who consider themselves physically "tall” and are focused on prevention will perform better in getting a good deal than individuals who consider themselves physically "short" and are focused on promotion.

H1b: Individuals who consider themselves physically "tall" and are focused on prevention will perform better in getting a good deal than individuals who consider themselves physically "tall" and are focused on promotion.

And when the comparison is between prevention-focused individuals with different vertical positions, the effect is believed to be more effective when individuals are in more vulnerable situations, which is when they are less motivated (physically tall) than when individuals are more motivated (physically short) to get a good deal.

H1c: Individuals who consider themselves physically "tall" and are focused on prevention will perform better in getting a good deal than individuals who consider themselves physically "short" and are focused on prevention.

For the foregoing reasons, it is considered that an individual's motivation to get a good deal may interfere with the relationships that are intended to be investigated. It is believed that an individual's motivation can play an important role in this proposed relationship, once motivation is intrinsically related to one's self-determination. According to Truong and McColl (2011), selfdetermination addresses the development and functioning of personality within social contexts, and the same authors state that human beings are active organisms with a natural tendency for psychological growth and development. Thus, according to Sheldon et al. (2004), individuals are motivated to satisfy their basic psychological needs, which are innate, universal and essential to well-being, which nourish and maintain this developmental process.

According to Cooper, Worthy and Maddox (2015), motivation is a key feature of decision making that is often studied in terms of individuals seeking to positive states and avoiding negative states. The most common definition of motivation, as simply increasing the effort of cognitive processing (in other words, the person endeavoring harder), is outdated. A deeper understanding of the complex interface between motivation and cognition is needed in order to theorize about motivation (Braver et al., 2014; Cooper et al., 2015). In addition, some authors (Higgins, 1997; 
BBR

17

314

Maddox \& Markman, 2010) argue that motivation operates at multiple levels and that the effects of motivation on individual's behavior derive from interactions between these levels.

Understanding motivation allows one to understand why consumers make certain purchasing decisions. Thus, motivation is a process that begins when a need is awakened, and the individual seeks to satisfy it (Fotiadis et al. 2016). This pursuit triggers a state of tension that drives the consumer to try to reduce or eliminate the need, which may be utilitarian or hedonic, and the desired end state is the target set by the individual (Jung et al., 2019).

An individual's willingness to expend energy in order to achieve a goal demonstrates his underlying motivation to achieve that goal (Ryan \& Deci, 2000). The forces that drive individuals to buy or use certain products or services are direct (Peñaloza et al., 2018). In some cases, people are unaware of the forces that guide them toward some products and push them away from others (Wang, Lin \& Spencer, 2019). Thus, some theories seek to explain certain modes of consumer behavior, highlighting that people have a limited amount of energy (Baumeister et al., 2008) to be directed towards certain goals, which may be, for example, price assessment to get the best deal.

Based on the different approaches for understanding an individual's motivation and considering that the motivation to get a good deal is much higher in some people than in others, the following hypothesis has been proposed:

H2: The motivation of the individual to get a good deal will play a mediating role in the relationship of the verticality metaphor and of the regulatory focus on product price assessments.

\section{EMPIRICAL RESEARCH}

\subsection{EXPERIMENT}

This study aims to analyze the influence of regulatory focus and the verticality metaphor on price assessments to achieve a good deal. Three hypotheses were prepared to be tested in this study, where we compared the performance of members of an individuals' group who consider themselves physically tall and are more focused on prevention in relation to the other manipulated groups. By the very nature of individuals, it is believed that there are people with more motivation than others to get a good deal. Thus, we also examine whether the motivation to get a good deal played a mediating role in the investigated theoretical model $(\mathrm{H} 2)$.

\subsubsection{Method}

Participants. A total of 151 students from a public university in the city of Sáo Paulo composed the sample for this study. The initial sample consisted of 160 students; however, 9 questionnaires were excluded from the survey due to with errors in filling the form ( 5 questionnaires) and because they presented failures in the attention check (4 questionnaires). The respondent profile is composed of $55 \%$ female and $45 \%$ male. The average age is 23 years old (Standard Deviation = 3.24), the individual average monthly income is $\mathrm{R} \$ 5,908.40$ (Standard Deviation $=4,193.28$ ), the family average income per capita is $\mathrm{R} \$ 9,404.54$ (Standard Deviation $=8,229.75$ ). $80.1 \%$ of the participants were single, $17.9 \%$ were married or in a stable relationship and only $2 \%$ were separated or divorced.

Drawing and procedures. A study was conducted with a drawing 2 (verticality metaphor: physically tall vs. physically short) $\mathrm{x} 2$ (regulatory focus: promotion vs. prevention) between subjects.

The manipulation of the verticality metaphor was operationalized through the guidelines of Ostinelli, Luna \& Ringberg (2014). Participants were asked to imagine a 100-story skyscraper. 
Inside this building they entered an elevator that had two different simulations. One simulation was for the individual to enter the elevator on the 10th floor and go up to the 30th floor. And the other simulation was for the individual to get in the elevator on the 50th floor and go down to the 30th floor. It should be noted that the destination floor was the same for both conditions in order to avoid possible confounding effects due to the height of the final destination. In addition, inside the elevator, participants had to imagine the door closing and the elevator moving up / down, also having the detail of the mental visualization of the red numbers changing (referring to floor) while the elevator goes up (11) $\ldots 12 \ldots 13 \ldots 14 \ldots 15 \ldots)$ or it goes down $(49 \ldots 48 \ldots$ $47 \ldots 46 \ldots 45 \ldots)$.

In order to check the manipulation of the verticality metaphor, participants had to answer the following questions immediately: Did you imagine the scene described in the text, to be answered on a seven-point agreement scale ( 1 = strongly disagree, 7 = agree fully); Have you been able to clearly visualize the elevator images to be answered on a seven point scale $(1=$ no image, $7=$ perfectly clear image); Did you have difficulty processing the text to be answered on a seven point scale $(1=$ hard to follow, 7 = easy to follow). "Considering as a point of reference the floor you were on, after getting on the elevator and going to the floor informed in the text, do you consider yourself in which position on the scale?", to be answered on a seven points scale ( $1=$ very low, 7 = very high).

The treatment of the regulatory focus was operationalized based on the guidelines of Freitas and Higgins (2002) and Pham and Avnet (2004). the focus on promotion was manipulated by asking participants to imagine their past and current hopes, dreams and aspirations of the past and of the present. The focus on prevention was manipulated by asking participants to imagine their duties, obligations and responsibilities. Immediately after the manipulation, based on the guidance of Chatterjee, Roy \& Malshe (2011), participants answered a question for manipulating checking [Which is more important for you to do? something I should (1) --- something I wanted (7)].

After the manipulation, a question was used to test the participants attention (attention check). This question, used to check participants' attention, was structured as follows: "We would like to know which food you find tastiest. In fact, we are wondering if the participants follow the instructions correctly. To show that you are following the instructions, choose the option "Other" from the list below and write lasagna: ( ) Noodles, ( ) Feijoada 'Brazilian Black Bean' Stew, ( ) Salads, ( ) Other. Which one?”

Then there was the presentation of the items on the BriefMood Introspection Scale (BMIS) by Mayer and Gashcke (1988). The mood served as one of the control variables of the study. Soon after, as a dependent variable, participants were asked to respond to the scenarios related to price assessment so that they could get a good deal (see the scenario description in the Appendix). This variable was measured through the development of four scenarios. In each scenario, the participant had to hit the correct answer in regard to getting a good deal. The participants' total hits in all scenarios were transformed into a measure (on a scale of 1 to 4 ) to analyze which individuals in each manipulated group performed best in this activity.

After that, other control variables of the study were measured (which are variables that could interfere with the results). The individuals had to answer, on a seven-point agreement scale, questions about Price Sensitivity (the product price has a determining role in your buying decision) and the ability in Mathematics (Do you consider your knowledge and mastery of mathematics satisfactory for your day-to-day decisions), as well as the mediating variable degree of Motivation for getting a good deal (Mark on the scale below your degree of motivation to get a good deal little motivated $=1$, very motivated $=7$ ). 
BBR

17

316

The study ended with a block of questions about the respondent's demographic profile and with an open-ended questions that sought to know if participants could find out how the different parts of the questionnaire were related and what was the purpose of the survey. Finally, the researcher performed the debriefing, revealing the research objectives and then releasing the participants.

\subsubsection{Results}

Manipulation checking. The verticality metaphor checking was performed by asking: "Considering, as a point of reference, the floor you were on, after entering the elevator and going to the floor informed in the text, do you consider yourself at which position on the scale below?" to be answered on a 7 -point scale $(1=$ too short; $7=$ too tall). Student's $\mathrm{t}$-test result showed that manipulation worked as expected $\left(M_{\text {physically_short }}=2.63\right.$, Standard Deviation $(S D)=0.897, N=76$; $\left.M_{\text {physically_tall }}=5.63, \mathrm{SD}=1.504, \mathrm{~N}=75 ; t(149)=14.836, p<0.01\right)$. And the research objectives were not identified by the participants, they were analyzed through the open questions at the end of the questionnaire.

The regulatory focus manipulation check showed that the focus on prevention has scored more the scale option that was related to this focus, "something I should do $=1$ ", and the focus on promotion has scored more toward the "something that I wanted to do $=7$ " $\left(\mathrm{M}_{\text {prevention= }}\right.$ 13.3, $\left.\mathrm{SD}=1.352, \mathrm{~N}=78 ; \mathrm{M}_{\text {promotion }}=4.82, \mathrm{SD}=1.540, \mathrm{~N}=73 ; \mathrm{t}(149)=7.194, \mathrm{p}<0.01\right)$.

Hypothesis test. To test the hypotheses $\mathrm{H} 1 \mathrm{a}, \mathrm{H} 1 \mathrm{~b}$ and $\mathrm{H} 1 \mathrm{c}$, the two way ANOVA was used. The results of this test compared to descriptive statistics are shown in Table 1.

Table 1

Descriptive Statistics of Study 1 (H1)

\begin{tabular}{llccc}
\hline \multicolumn{4}{c}{ Dependent Variable: Getting a Good Deal } \\
\hline Regulatory Focus & Verticality Metaphor & Average & Standard Deviation & N \\
\hline \multirow{5}{*}{ Focus on promotion } & Physically tall & 2,53 & 0,788 & 34 \\
& Physically short & 2,64 & 0,932 & 39 \\
& Total & 2,59 & 0,863 & 73 \\
& Physically tall & 3,27 & 1,017 & 41 \\
Focus on prevention & Physically short & 2,49 & 0,891 & 37 \\
& Total & 2,90 & 0,759 & 78 \\
& Physically tall & 2,93 & 0,759 & 75 \\
& Physically short & 2,57 & 0,971 & 76 \\
& Total & 2,75 & 0,889 & 151 \\
\hline
\end{tabular}

Source: Research Data

The ANOVA results show a major effect of regulatory focus $\left(\mathrm{M}_{\text {prevention }}=2.90, \mathrm{SD}=0.759\right.$, $\left.\mathrm{N}=78 ; \mathrm{M}_{\text {promotion }}=2.59, \mathrm{SD}=0.863, \mathrm{~N}=73\right)$ on the price assessment to get a good deal. $(\mathrm{F}$ $(1,147)=4.589, \mathrm{p}<0.05, \eta \mathrm{p} 2=0.030)$. The same was true for the verticality metaphor variable $\left(\mathrm{M}_{\text {physically_tall }}=2.93, \mathrm{SD}=0.759, \mathrm{~N}=75 ; \mathrm{M}_{\text {physically_short }}=2.57, \mathrm{SD}=0.971, \mathrm{~N}=76 ; \mathrm{F}(1,147)=\right.$ $6.036, \mathrm{p}<0.05, \eta \mathrm{p} 2=0.039)$. Figures 1 and 2 illustrate the interaction between the variables. In addition to these results, intergroup differences tests (between means) were performed through the Student's t-test of the two manipulated groups. In the verticality metaphor groups, individuals who consider themselves physically tall obtained the following results for the two regulatory foci $\mathrm{M}_{\text {promotion }}=2.53(\mathrm{SD}=0.788)$ and $\mathrm{M}_{\text {prevention }}=3.27(\mathrm{SD}=0.549)$, these results showed significant 
differences as to statistics $(t(73)=-4.773, p<0.01)$. On the other hand, individuals who consider themselves physically short showed no differences between the means in relation to the regulatory focus $\left(\mathrm{M}_{\text {promotion }}=2.64, \mathrm{SD}=0.932 ; \mathrm{M}_{\text {prevention }}=2.49, \mathrm{SD}=1.017 ; \mathrm{t}(74)=0.691, \mathrm{p}>0.05\right)$. In the two way ANOVA with variables having only two levels, it is not necessary to assess the contrasts and the post hoc tests because any significant effect will only reflect differences between these two levels (because there are less than three levels or groups).

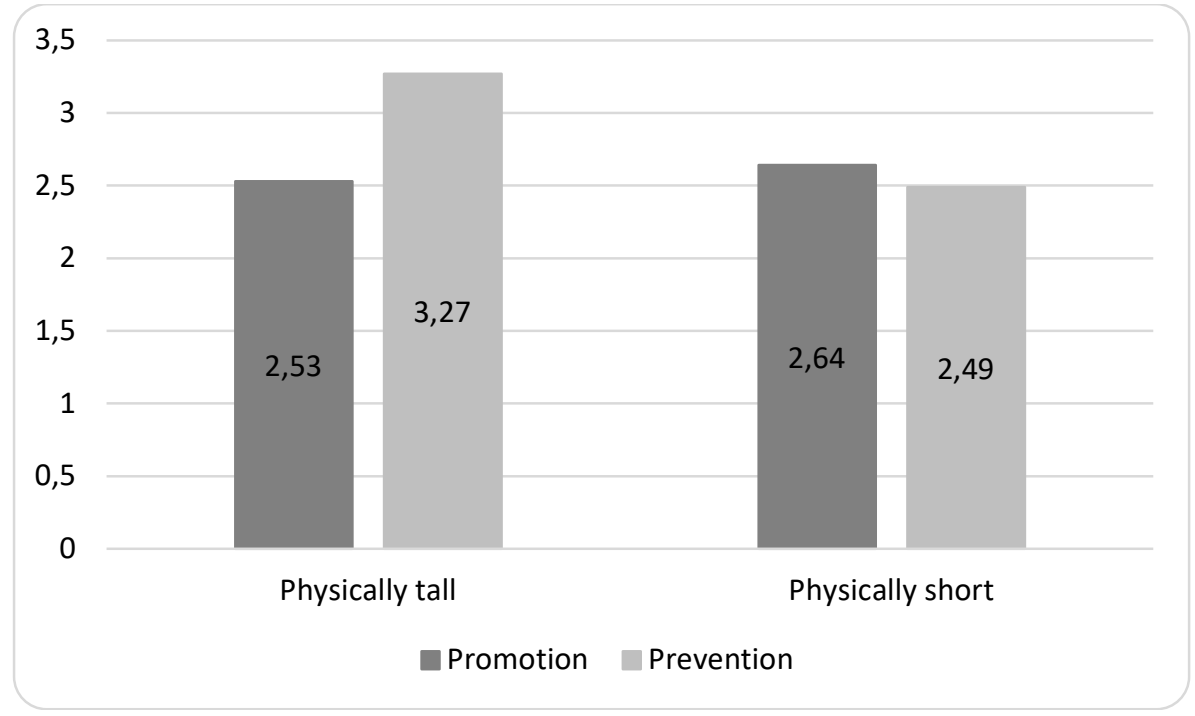

Figure 1. Interaction of the Study variables 1 (H1)

Source: Research Data.

However, the interaction between the independent variables had an effect on the dependent variable of getting a good deal $\left(F(1,147)=10.727, p<0.01, \eta_{\mathrm{p}}{ }^{2}=0.068\right)$. These results, as well as the information from the averages in Table 1 and Figure, provide support for confirming hypotheses H1a, H1b, and H1c.

Additional Tests. To test the inclusion of control variables, the ANCOVA was used. The inclusion of the control variable on the $\operatorname{mood}(\alpha=0,755)$ showed no change in the results found to test $\mathrm{H} 1\left(F(1,146)=0,032, p>0,05, \eta_{\mathrm{p}}{ }^{2}=0,000\right)$. The descriptive statistics of the variables we used as control and moderating variables can be seen in Table 2 .

The variable price sensitivity of the individual had a major effect on price assessment to get a good deal $\left(F(1,146)=4,501, p<0,05, \eta_{\mathrm{p}}{ }^{2}=0,030\right)$, however, its inclusion in the model did not change the results previously found (see Table 3 ). 
BBR

17

318

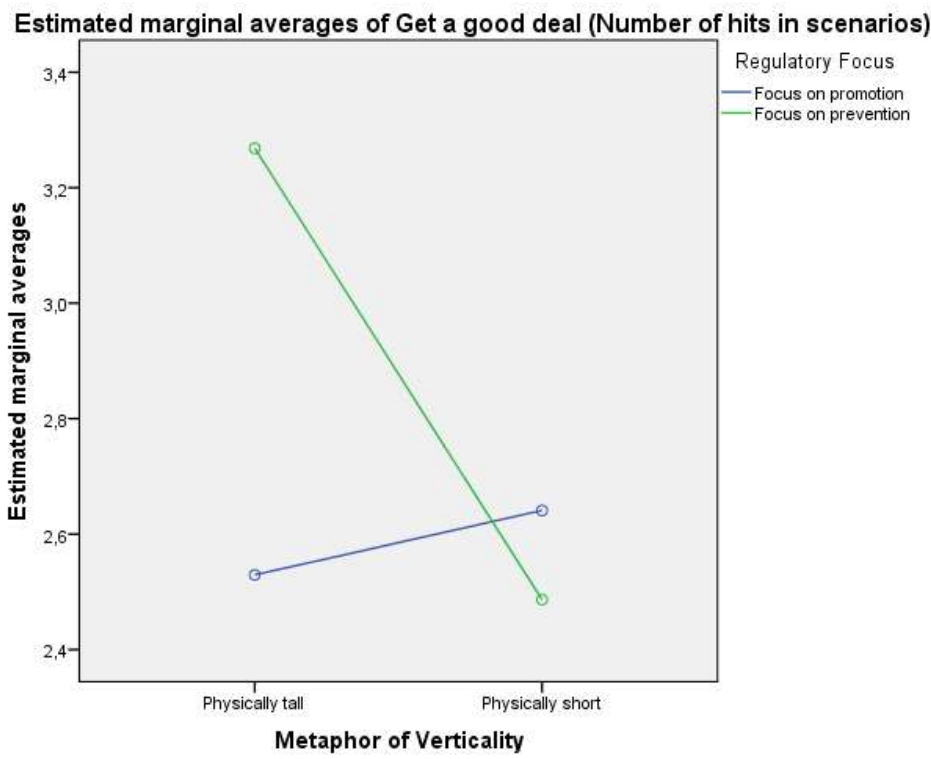

Figure 2. Crossing in the Interaction of the variables of the Study 1 (H1)

Source: Research Data.

Table 2

Descriptive statistics of the control variables and the mediator variable

\begin{tabular}{lccccc}
\hline Variables & $\mathrm{N}$ & Minimum & Maximum & Average & Standard deviation \\
\hline Effort (time - in minutes) & 151 & 3 & 34 & 8,70 & 3,932 \\
Price Sensitivity & 151 & 1 & 7 & 5,84 & 1,195 \\
Mathematical ability & 151 & 1 & 7 & 5,68 & 1,309 \\
Humor (Compound) & 151 & 2 & 6 & 3,52 & 0,649 \\
Motivation (mediator) & 151 & 1 & 7 & 5,97 & 1,474 \\
\hline
\end{tabular}

Source: Research Data.

Table 3

Effect Tests (Price Sensitivity Control)

\begin{tabular}{|c|c|c|c|c|c|c|}
\hline \multicolumn{7}{|c|}{ Dependent variable: Get a good deal (Number of hits in the scenarios) } \\
\hline Source & $\begin{array}{l}\text { Type III Sum } \\
\text { of Squares }\end{array}$ & Df & $\begin{array}{l}\text { Middle } \\
\text { Square }\end{array}$ & $\mathrm{F}$ & Sig. & Partial Eta-squared \\
\hline Model corrected & $18,773^{\mathrm{a}}$ & 4 & 4,693 & 6,875 & 0,000 & 0,159 \\
\hline Ordered at Source & 24,609 & 1 & 24,609 & 36,051 & 0,000 & 0,198 \\
\hline Price sensitivity & 3,073 & 1 & 3,073 & 4,501 & 0,036 & 0,030 \\
\hline Focus & 3,553 & 1 & 3,553 & 5,204 & 0,024 & 0,034 \\
\hline Vertical & 3,721 & 1 & 3,721 & 5,451 & 0,021 & 0,036 \\
\hline focus * vertical & 7,339 & 1 & 7,339 & 10,750 & 0,001 & 0,069 \\
\hline Error & 99,664 & 146 & 0,683 & & & \\
\hline Total & 1259,000 & 151 & & & & \\
\hline Total corrected & 118,437 & 150 & & & & \\
\hline
\end{tabular}

Source: Research Data.

Note. (a) R squared $=0,159$ (R squared adjusted $=0,135$ ) 
For the study it was added the control variable on the mathematics ability of the individual (see Table 4). This control variable also had a major effect on price assessment for getting a good deal $\left(F(1,146)=14,794, p<0,01, \eta_{p}^{2}=0,092\right)$, but its inclusion did not affect previous findings.

Table 4

Effect Tests (Math Skill Control)

\begin{tabular}{|c|c|c|c|c|c|c|}
\hline \multicolumn{7}{|c|}{ Dependent variable: Get a good deal (Number of hits in the scenarios) } \\
\hline Source & $\begin{array}{c}\text { Type III Sum } \\
\text { of Squares }\end{array}$ & Df & $\begin{array}{l}\text { Middle } \\
\text { Square }\end{array}$ & $\mathrm{F}$ & Sig. & Partial Eta-squared \\
\hline Model corrected & $25,153^{\mathrm{a}}$ & 4 & 6,288 & 9,842 & 0,000 & 0,212 \\
\hline Ordered at Source & 19,878 & 1 & 19,878 & 31,111 & 0,000 & 0,176 \\
\hline Mathematical ability & 9,453 & 1 & 9,453 & 14,794 & 0,000 & 0,092 \\
\hline Focus & 2,477 & 1 & 2,477 & 3,877 & 0,051 & 0,026 \\
\hline Vertical & 5,393 & 1 & 5,393 & 8,440 & 0,004 & 0,055 \\
\hline focus ${ }^{*}$ vertical & 8,654 & 1 & 8,654 & 13,545 & 0,000 & 0,085 \\
\hline Error & 93,284 & 146 & 0,639 & & & \\
\hline Total & 1259,000 & 151 & & & & \\
\hline Total corrected & 118,437 & 150 & & & & \\
\hline
\end{tabular}

Source: Research Data.

Note. (a) R squared $=0,212$ ( $\mathrm{R}$ squared adjusted $=0,191)$

Finally, the control variable of the participant effort was also used to assess prices and get a good deal. The effort variable was measured by the time spent in solving the four scenarios. The longer the time, the greater the effort to complete the task. The variable effort had no major effect on price assessment to get a good deal $\left(F(1,146)=0,035, p>0,05, \eta_{p}{ }^{2}=0,000\right)$, nor did it affect the relationship previously identified in the model.

About the test of moderate mediation, the variable of motivation was used to get a good deal as the mediating variable. The macro PROCESS SPSS (Model 8; Hayes, 2013) was used for this test. Figure 3 shows the model of moderate mediation of the study 1 .

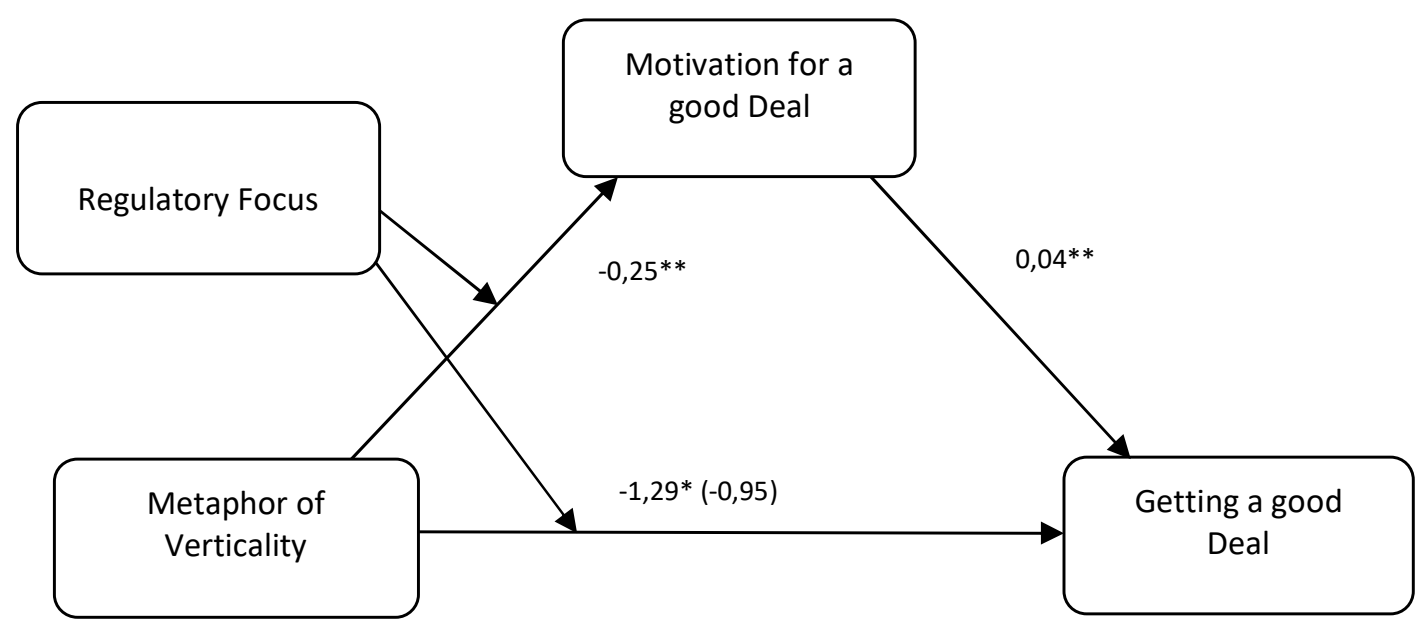

Figure 3. Moderate Mediation of the Study

Source: Prepared by the authors.

Note. Figures in brackets show the coefficient after the inclusion of the mediating variable.

${ }^{*} \mathrm{p}<0,01,{ }^{* *} \mathrm{p}>0,05$ 
BBR

17

320

The model (Figure 3) has, as its independent variable, $(\mathrm{X})$ the metaphor of verticality, which was transformed into dummy $(0=$ physically short; 1 = physically tall), the regulatory focus was the moderating variable (W), also transformed into dummy. $(0=$ prevention; 1 = promotion $)$, the motivation of the individual to get a good deal was the mediating variable $(\mathrm{M})$ and the dependent variable $(\mathrm{Y})$ was the performance of the individuals in the price assessment to get a good deal.

The test result shows that there was no statistical significance of the verticality metaphor interaction and of the regulatory focus to predict individuals' motivation to get a good deal ( $\beta$ $=-0,25, t(147)=-0,53, p>0,05, \mathrm{LLCI}=-1,21 ; \mathrm{ULCI}=0,69)$. The direct effect of individuals' motivation was also not statistically significant for predicting the performance in getting a good deal $(\beta=0,04, t(147)=0,79, p>0,05, \mathrm{LLCI}=-0,05$; ULCI $=0,13)$. The low values of the coefficients $(-0.25$ and 0.04$)$ provide, in anticipation, an indication that the variable Motivation will not play a mediating role in the direct relationship of the interaction (verticality $\mathrm{x}$ focus) about getting a good deal.

The total effect of the interaction metaphor of verticality $\times$ regulatory focus was statistically significant for predicting price assessments for a good deal $(\beta=-0,89, t(147)=-3,27, p<0,01$, LLCI $=-1,43$; ULCI $=-0,35)$. However, it is important to highlight that hypothesis $\mathrm{H} 2$ expected a positive interaction, and the beta coefficient shows that this interaction was negative, showing that one variable decreases the effect of the other on the interaction. Moreover, hypothesis $\mathrm{H} 2 \mathrm{did}$ not get support for its confirmation because when there was the inclusion of a mediator variable (motivation to get a good deal) in the model, the interaction and the effect on the dependent variable remained virtually the same as previously identified $(\beta=-0,88, t(146)=-3,23, p<0,01$, LLCI $=-1,43$; ULCI $=-0,34)$.

\subsubsection{Discussion}

The study aimed to investigate the influence of the regulatory focus, and of the verticality metaphor on price assessment to get a good deal. It was considered here that getting a good deal is getting the benefit of the desired product at the lowest possible price (Schindler 1989). The group that got the best performance in the assessment of price scenarios was the group predicted by this study, individuals who consider themselves physically tall and focused on prevention.

The activity of assessing prices to get a good deal becomes relevant to the ego, because of the individual's search for success an action. Assessing price arouses enthusiasm and excitement for many people, thus creating greater involvement of the individual in the activity (Darke \& Dahl, 2003). Getting a good deal on the price assessment leaves consumers feeling competent about their performance (Nakhata \& Kuo, 2016). This context, that involves the individual to get a good deal can contribute to the explanation of the fact that the individual who considers himself physically tall and is focused on prevention achieved the best performance in the activity.

Since the individual who considers himself physically tall has low motivation to perform some tasks (Ostinelli, Luga \& Ringberg, 2014), the focus on prevention has contributed to restoring an individuals' motivation by the motivational profile of this focus on being aware of decisions that possibly bring negative results (Crowe \& Higgins, 1997; Roy \& Naidoo, 2017). In addition, the focus on prevention moderates the features of individuals who consider themselves physically tall, having in view a more conservative approach toward their decisions, that is, it causes individuals with high motivation to have more moderation in their decisions.

The individual's motivation to get a good deal did not interfere with the relationship found earlier. It was believed that there could be a mediating role for this construct because it is the motivation that drives individuals to get what they want, making them more determined to achieve something (Truong \& McColl, 2011). Motivation explains people's behavior, representing the 
reasons for actions, desires and needs (Landry et al., 2017). But, seeing as motivation did not, in our study, play a mediating role, it may considered that people are motivated to meet basic and essential needs (Scheldon et al., 2004), and for the scope of this study there is no difference in this motivation intensity among the treatment groups to get a good deal.

Furthermore, as an additional analysis, the group that had the worst performance among the treatment groups analyzed was the group of individuals who consider themselves physically short and are focused on prevention. This result may be explained by the perception of the task as something unattractive to restoring the ego (Mittal \& Biswas, 2016) or because the interaction between the two profiles, physically short and prevention, has not driven the individuals to act with a lot of motivation in order to achieve success in the task. The combination of the high motivation of the individuals who consider themselves physically short (Ostinelli, Luna \& Ringberg (2014), with the conservative feature of the focus on prevention may have left the individuals more repressed to perform the task. The result of the best performance of the group of individuals who consider themselves physically tall and focused on prevention has as its basis the balance between the different profiles: a low motivation being moderated by the caution of the focus on prevention, in avoiding negative outcomes.

\section{CONCLUSION}

This research sought to analyze how the metaphor of verticality influences the price assessment performed by individuals to get a good deal, with the regulatory focus having a moderating role in this relationship. The results show that the treatment group, with the individual who considers himself physically tall and focused on prevention, was the best performer in the price assessment to get a good deal. The originality of this research lies in identifying the behavioral characteristics of individuals who are able to mitigate changes in people's motivations, when exposed to mental simulations of verticality, in order to obtain a good deal. The research findings allowed us to check the effects of the verticality metaphor on the way individuals assess prices, presenting increases and decreases in their motivations throughout the day, when these momentary changes occur, individuals are urged to restore the "self".

The metaphor is increasingly used to understand consumer behavior. According to Kemp (2015), a sensory metaphor is a specific sub-area of sensory marketing and the subtle and incidental bodily experiences can unconsciously affect the thoughts, social perceptions, attitudes, inferences and judgments. The strength of the sensory metaphor can be seen in the study by Williams and Bargh (2008), who noticed that when a person held a warmer drink as opposed to a cooler one, they perceived other people as more compassionate and more caring. In other words, experiencing, subconsciously, physical warmth, promotes interpersonal warmth. The results found in this research extend these findings on the use of metaphor to understand the behaviors of individuals.

The metaphor of verticality had previously been studied in consumer behavior situations (Ostinelli, Luna \& Ringberg, 2014; Aggarwal \& Zhao, 2015; Machiels \& Orth, 2017), but its impact on price assessments had not yet been investigated. Thus, this research contributed to understanding how daily changes in motivation could influence price assessments, identifying that individuals with low motivation, who were prevention focused were able to get the best results in these assessments. Finally, the regulatory focus is commonly used as a moderating variable. In this study, this role had an extension, since the construct was able to mitigate the effects of verticality metaphor on price assessments. 
BBR

17

A limitation of this research that can be highlighted is relative to the sample. A random sample could have also been used, other than just undergraduate students. Peterson (2001) states that when the sample is very homogeneous, as is the case with the undergraduate sample used, it is also important to apply the study to other samples, with different profiles, to give more credibility to the data. In addition to this limitation mentioned above there is another: no other way to manipulate the verticality was tested to see if it would more effectively influence individuals, such as using audio to describe scenarios instead of the use of texts.

Finally, as a recommendation for a future research proposal, one could investigate the relationships of the variables of the verticality metaphor and the regulatory focus for impulse decision situations, either for purchase or consumption. If it is for purchase impulse, a small amount of money should be provided to the participants, so that the decision becomes closer to reality, allowing greater involvement of the individual. And if it is for consumption impulse, the tasting of products that raise the temptation to consume should be encouraged to make the decision more challenging.

\section{REFERENCES}

Aaker, J. L. \& Lee, A. Y. (2001). "I" seek pleasure and "we" avoid pains: the role of self-regulatory goals in information processing and persuasion. Journal of Consumer Research, 28 33-49.

Aggarwal, P. \& Zhao, M. (2015). Seeing the big picture: the effect of height on the level of construal. Journal of Marketing Research, 52(1) 120-133.

Ariely, D. (2008). Predictably irrational: the hidden forces that shape our decisions. New York, NY: HarperCollins.

Audrain-Pontevia, A. F., N'Goala, G. \& Poncin, I. (2013). A good deal online: the impacts of acquisition and transaction value on e-satisfaction and e-loyalty. Journal of Retailing and Consumer Services, 20(5) 445-452.

Avlonitis, G. \& Indounas, K. A. (2007). An empirical examination of the pricing policies and their antecedents in the services sector. European Journal of Marketing, 41(8) 740-764.

Baumeister, R. F., Sparks, E. A., Stillman, T. F., \& Vohs, K. D. (2008). Free will in consumer behavior: self-control, ego depletion, and choice. Journal of Consumer Psychology, 18, 4-13.

Berkman, H. W., Lindquist, J. D. \& Sirgy, M. J. (1997). Consumer behavior. Chicago: NTC Publishing Group.

Bicen, P. \& Madhavaram, S. (2013). Research on smart shopper feelings: an extension. Journal of Marketing Theory and Practice, 21(2) 221-234.

Braver, T. S., Krug, M. K., Chiew, K. S., Kool, W., Westbrook, J. A., Clement, N. J., et al (2014). Mechanisms of motivation-cognition interaction: Challenges and opportunities. Cognitive, Affective, \& Behavioral Neuroscience, $14(2), 443-472$.

Chatterjee, S., Roy, R. \& Malshe, A. V. (2011). The role of regulatory fit on the attraction effect. Journal of Consumer Psychology, 21 473-481.

Chen, S. F., Monroe, K. B., \& Lou, Y. C. (1998). The effects of framing price promotion messages on consumers' perceptions and purchase intentions. Journal of Retailing, 74(3) 353-372.

Cooper, J. A., Worthy, D. A., \& Maddox, W. T. (2015). Chronic motivational state interacts with task reward structure in dynamic decision-making. Cognitive Psychology, 83, 40-53.

Costa, M. F., Farias, S. A., \& Angelo, C. F. (2018). Chronic regulatory focus: Resist impulse consumption or let it happen? Revista Brasileira de Gestão de Negócios, 20, 619-637. 
Crowe, H. \& Higgins, E. T. (1997). Regulatory focus and strategic inclinations: promotion and prevention in decision-making. Organizational Behavior and Human Decision Processes, 69(2) 117-132.

Darke, P. R., \& Dahl, D. W. (2003). Fairness and discounts: the subjective value of a bargain. Journal of Consumer Psychology, 13 328-338.

De Toni, D. \& Mazzon, J. A. (2013). Imagem de preço de produto: proposição de modelo conceitual. Revista de Administração da USP, 48(3) 454-468.

Elliot, A. J \& Covington, M. (2001). Approach and avoidance motivation. Educational Psychology Review, 13(2), 73-92.

Freitas, A. L. \& Higgins, E. T. (2002). Enjoying goal-directed action: The role of regulatory fit. Psychological Science, 13(1), 1-6.

Fotiadis, A., Xie, L., Li, Y. \& Huan, T. C. (2016). Attracting athletes to small-scale sports events using motivational decision-making factors. Journal of Business Research, 69(11), 5467-5472.

Hanke, S., Rohmann, E. \& Förster, J. (2019). Regulatory focus and regulatory mode - Keys to narcissists' (lack of) life satisfaction? Personality and Individual Differences, 138, 109-116.

Hanna, R. C., Lemon, K. N. \& Smith, G. E. (2019). Is transparency a good thing? How online price transparency and variability can benefit firms and influence consumer decision making. Business Horizons, 62(2), 227-236.

Hayes, A. F. (2013). Introduction to mediation, moderation, and conditional process analysis. New York: The Guildford Press.

Higgins, E. T. (1997). Beyond pleasure and pain. American Psychologist, 52, 1280-1300.

Juan, Y. K, Hsu, Y. H. \& Xie, X. (2017). Identifying customer behavioral factors and price premiums of green building purchasing. International Marketing Management, 64, 36-43.

Jung, D., Erdfelder, E., Bröder, A. \& Dorner, V. (2019). Differentiating motivational and cognitive explanations for decision inertia. Journal of Economic Psychology, 72, 30-44.

Kahneman, D. \& Tversky, A. (1979). Prospect theory: an analysis of decision under risk. Econometrica, $47(2)$ 263-292.

Kemp, L. C. M. (2015). 'It's a cold hard world': the subconscious influence of sensory metaphors on consumer responses. Master thesis, University of Twente, Enschede, Netherlands.

Landry, T. A., Gagné, M., Forest, J., Guerrero, S., Séguin, M. \& Papachristopoulos, K. (2017). The relation between financial incentives, motivation, and performance: an integrative SDT-based investigation. Journal of Personnel Psychology, 16(2), 61-76.

Machiels, C. J. A. \& Orth, U. R. (2017). Verticality in product labels and shelves as a metaphorical cue to quality. Journal of Retailing and Consumer Services, 37, 195-203.

Maddox, W. T., \& Markman, A. B. (2010). The motivation-cognition interface in learning and decision making. Current Directions in Psychological Science, 19(2), 106-110.

Maehr, M. L \& Mayer, H. (1997). Understanding motivation and schooling: where we've been, where we are, and where we need to go. Educational Psychology Review, 9(44) 371-409.

Marketing Science Institute - MSI. (2012-2014). Research Priorities. http://www.msi.org/research/ msi-research-priorities/priority-1-insight-into-people-in-their-roles-as-consumers/ 
BBR

17

Mittal, B. \& Biswas, D. (2016). Psychographics of comparison shoppers. Journal of Consumer Marketing, 33(1) 20-31.

Mosteller, J. \& Poddar, A. (2017). To share and protect: using regulatory focus theory to examine the privacy paradox of consumer's social media engagement and online privacy protection behaviors. Journal of Interactive Marketing, 39, 27-38.

Nakhata, C., \& Kuo, H.-C. (2017). Consumer avoidance of specially priced items during social coupon redemption. Journal of Retailing and Consumer Services, 34, 287-293.

Nunes, T. M., Flores, S. A. M. \& Silva, A, C. J. (2018). A aversão à perda e o excesso de confiança sob a ótica do gênero. Consumer Behavior Review, 2(1), $42-54$.

Ostinelli, M., Luna, D. \& Ringberg, T. (2014). When up brings you down: the effect of imagined vertical movements on motivation, performance, and consumer behavior. Journal of Consumer Psychology, 24(2), 271-283.

Papi, M. (2018). Price competition with satisficing consumers. International Journal of Industrial Organization, 58, 252-272.

Peñaloza, V., Portela, M., S. O., Gerhard, F. \& Quezado, I. (2018). Representação social da compra por impulso por consumidores de baixa renda. Consumer Behavior Review, 2(1), 1-12.

Pham, M. T. \& Avnet, T. (2004). Ideals and oughts and the reliance of affect versus substance in persuasion. Journal of Consumer Research, 30(4).

Pham, M. T. \& Higgins, E. T. (2005). Promotion and prevention in consumer decision making: State of the art and theoretical propositions. In: Inside consumption: Frontiers of research on consumer motives, goals, and desires. S. Ratneshwar, David Glen Mick, (eds.), Routledge.

Pham, M. T. \& Chang, H. (2010). Regulatory focus, regulatory fit, and the search and consideration of choice alternatives. Journal of Consumer Research, 37(4), 626-640.

Roy, R. \& Phau, I. (2014). Examining regulatory focus in the information processing of imagery and analytical advertisements. Journal of Advertising, 43(4), 371-381.

Roy, R. \& Naidoo, V. (2017). The impact of regulatory focus and word of mouth valence on search and experience attribute evaluation. European Journal of Marketing, 51(8), 1-33.

Ryan, R. M., \& Deci, E. L. (2000). Self-determination theory and the facilitation of intrinsic motivation, social development, and well-being. The American Psychologist, 55(1), 68-78.

Sarkar, S. (2016). Consumer welfare and the strategic choice of price cap and leverage ratio. The Quarterly Review of Economics and Finance, 60, 103-114.

Schindler, R. M. (1989). The excitement of getting a bargain: some hypotheses concerning the origins and effects of smart-shopper feelings. Advances in Consumer Research, 16(1), 447-453.

Schindler, R. M. (1998). Consequences of perceiving oneself as responsible for obtaining a discount: evidence for smart-shopper feelings. Journal of Consumer Psychology, 7(4), 371-392.

Sheldon, K. M., Ryan, R. M., Deci, E. L., Kasser, T. (2004). The independent effects of goal contents and motives on well-being: it's both what you pursue and why you pursue it. Personality and Social Psychology Bulletin, 30(4), 475-486.

Silva, M. J. B., Santana, S. A. \& Costa, M. F. (2018). Com que roupa eu vou? Compreendendo o consumo de vestimentas realizado por empresárias de confecçóes. Revista Brasileira de Marketing, $17,788-805$. 
Sun, J., Keh, H. T. \& Lee, A. Y. (2019). Shaping consumer preference using alignable attributes: The roles of regulatory orientation and construal level. International Journal of Research in Marketing, $36(1), 151-168$.

Trudel, R., Murray, K. B. \& Cotte, J. (2012). Beyond expectations: the effect of regulatory focus on consumer satisfaction. International Journal of Research in Marketing, 29, 93-97.

Truong, Y. \& McColl, R. (2011). Instrinsic motivations, self-esteem, and luxury goods consumption. Journal of Retailing and Consumer Services, 18(6), 555-561.

Wang, X., Lin, X., \& Spencer, M. K. (2019). Exploring the effects of extrinsic motivation on consumer behaviors in social commerce: Revealing consumers' perceptions of social commerce benefits. International Journal of Information Management, 45, 163-175.

Williams, L. E. \& Bargh, J. A. (2008). Experiencing physical warmth promotes interpersonal warmth, Science, 322(5901), 606-607.

Zhu, R. \& Meyers-Levy, J. (2007). Exploring the cognitive mechanism that underlies regulatory focus effects. Journal of Consumer Research, 34, 89-96.

Zou, L. W. \& Chan, R. Y. K. (2019). Why and when do consumers perform green behaviors? An examination of regulatory focus and ethical ideology. Journal of Business Research, 94, 113-127. 
Getting a good deal

The scenarios can be checked below.

Scenario 1

You go to the supermarket to buy milk powder. Once you get there, you will find on the shelves of the establishment several types of milk brand packaging that you want to buy. A bag of milk powder contains $200 \mathrm{~g}$ and costs $\mathrm{R} \$ 3.50$. The other has $800 \mathrm{~g}$ and costs $\mathrm{R} \$ 14.90$. And a third bag has $500 \mathrm{~g}$ and costs $\mathrm{R} \$ 10.80$, in addition, in the latter bag of milk there is the following sentence: "Pay $500 \mathrm{~g}$ and take $100 \mathrm{~g}$ for free" (totaling $600 \mathrm{~g}$ of the product).

Whereas in all packages there is the same type and brand of milk, and you need to take home $800 \mathrm{~g}$ of the product, What is the best option to get the milk at the lowest price?

a) Packing with $800 \mathrm{~g}$.

b) The package with $500 \mathrm{~g}$ plus $100 \mathrm{~g}$, having to take a further $200 \mathrm{~g}$.

c) Take four packages of $200 \mathrm{~g}$.

\section{Scenario 2}

In a shop window you see a shirt on a mannequin that draws your attention. Thus, you decide to enter the store and ask the price. The seller says the shirt costs $\mathrm{R} \$ 45.00$ and that he can offer other prices, depending on how many shirts will be purchased. He says that if you take three shirts, the price is $R \$ 125.00$, if you take four shirts the price is $R \$ 200.00$ and you get another shirt for free.

Assuming you need to buy four shirts, because you will use them to get to your work, What is the best option to get the shirts you need at the best price?

a) The option with three shirts, having to take one more unit at $R \$ 45.00$.

b) The option with four shirts and one free.

c) Take four shirts, each of which costing $\mathrm{R} \$ 45.00$.

\section{Scenario 3}

You are in the mood for Chinese food for lunch; when you come to a shopping mall food court, you realize that there are three Chinese restaurants with different prices, and they are practically the same in relation to the quality and taste of food. In restaurant $A, 1 \mathrm{~kg}$ costs $\mathrm{R} \$ 48.00$ and the soft drink $\mathrm{R} \$ 5.00$. In restaurant $\mathrm{B}, 1 \mathrm{~kg}$ costs $\mathrm{R} \$ 58,00$ and if you take as from $500 \mathrm{~g}$ or more the soft drink is free. In restaurant $C, 1 \mathrm{~kg}$ costs $\mathrm{R} \$ 50.00$ and the soft drink costs $\mathrm{R} \$ 3.00$.

Whereas you will consume exactly $500 \mathrm{~g}$ of food and also a soft drink, what is the best option to get the food and the soft drink at the lowest price?
a) The restaurant $A$.
b) The restaurant $B$.
c) The restaurant $\mathrm{C}$.

\section{Scenario 4}

You want to watch a movie premiere together with your family (you, your spouse and your child). Upon arriving at the box office, you realize that there are packages with different prices. Option 1 consists of buying the tickets individually, each one costs $\mathrm{R} \$ 20.00$ and your child pays half a ticket, $\mathrm{R} \$ 10.00$ This option 1 also offers popcorn and soft drink. The price of popcorn in the large package is $R \$ 15.00$ and soft drink $R \$ 10.00$. Option 2 is a promotion for 
the family (with three members) that costs $\mathrm{R} \$ 55.00$, this amount already includes popcorn in large package and the soft drink costs $\mathrm{R} \$ 8.00$. Option 3 is another promotion for the family (with three members) that costs $\mathrm{R} \$ 62.00$, this amount also includes popcorn in large package and the soft drink is free.

Considering that you will buy, besides the three tickets, a large popcorn package and a soft drink, which is the option at the best price (lowest cost)?
a) Option 1 .
b) Option 2.
c) Option 3 .

To answer the four scenarios for getting a good deal, participants could only use the scratch paper and pencil that were handed at the beginning of the experiment. 